\title{
A sebecosuchian in a middle Eocene karst with comments on the dorsal shield in Crocodylomorpha
}

\author{
Jeremy E. Martin \\ Acta Palaeontologica Polonica 60 (3), 2015: 673-680 doi:http://dx.doi.org/10.4202/app.00072.2014
}

Isolated elements comprising a set of ziphodont teeth and osteoderms from the middle Eocene karst deposit of Lissieu, France are assigned to either Iberosuchus sp. or Bergisuchus sp., poorly known crocodylomorphs of possible sebecosuchian affinities. A general survey of dorsal osteoderm variability among Crocodylomorpha points to the similarity between the osteoderms from Lissieu and those of some Cretaceous notosuchians, notably the sebecosuchian Baurusuchus. Such isolated osteoderms represent a useful tool for identifying non-eusuchian crocodylomorphs in post-Cretaceous deposits. Relying on the distinctive morphology of these osteoderms might help augmenting the extremely scant fossil record of Paleogene sebecosuchians in Europe, thus improving the spatiotemporal resolution of this group. At least three types of predators coexisted in the ecosystem of Lissieu, which indicates that in the middle Eocene of Europe, carnivoran mammals were not the exclusive predators in terrestrial habitats and shared resources with a ground bird and a sebecosuchian. This faunal composition is comparable to contemporaneous ecosystems in South America.

Key words: Crocodilia, Sebecosuchia, Paleogene, Eocene, France.

Jeremy E. Martin [jeremy.martin@ens-lyon.fr,], Laboratoire de Géologie de Lyon: Terre, Planète, Environnement, UMR CNRS 5276 (CNRS, ENS, Université Lyon1), Ecole Normale Supérieure de Lyon, 69364 Lyon cedex 07, France.

This is an open-access article distributed under the terms of the Creative Commons Attribution License (for details please see creativecommons.org), which permits unrestricted use, distribution, and reproduction in any medium, provided the original author and source are credited. 
Fof Full text $(429.7 \mathrm{kB})$ 